\title{
Online Diaries and Blogs
}

\section{JILL WALKER RETTBERG}

\begin{abstract}
Jill Walker Rettberg
Working paper scheduled for publication in The Diary, Indiana UP 2019/20.

Suggested citation:

Rettberg, Jill Walker. "Online Diaries and Blogs." In The Diary, edited by Batsheva BenAmos and Dan Ben-Amos. Bloomington: Indiana University Press, 2019/20. Pre-print September 2016, revised 2018.
\end{abstract}

I stood on the balcony of a city apartment in Melbourne. There was a party inside on this autumn evening in 2001, and I had just met the woman who stood next to me. She leaned over the balcony railing, holding a black device in her outstretched hands. She gazed from the cloudy skies to her device, anxiously peering at its tiny display. She frowned and held the device up towards the skies.

'What are you doing?' I asked her.

'I can't get the coordinates,' she replied, distractedly. 'Maybe the clouds make it harder to connect to the satellites.'

The device, she explained, was a GPS tracker, a primitive turn-of-thecentury consumer version of the technology that is now built into every smartphone. Curious, I asked her why she wanted to know her location. We knew where we were, after all. On a balcony in a friend's apartment. We weren't lost.

She laughed a little. 'Well,' she said, 'it's like a diary. I log places I've been, and then I can see them on a map. It's a way for me to remember my life.' She 
looked a little defensive, as though others had scoffed at this, but I smiled. I understood immediately.

As technologies and cultures change, so do the ways we record our lives. Philippe Lejeune noted that diaries depend on the availability of paper, a technology, but also on the existence of a culture with a notion not only of the self but of accounting and keeping track of items and changes ${ }^{1}$. In his book Writing the Self, Peter Heehs describes how the Renaissance accountants began to annotate the numbers they recorded in their ledgers by adding personal details that in time grew into diaries ${ }^{2}$. Cameras led to photo albums, which are a kind of family diary that combines photographs with written descriptions. The web and smartphones have made new genres possible, like online diaries, blogs, selftracking apps and social media.

In the last decade, social media have become mainstream, and while internet access is still unevenly distributed, about $40 \%$ of people worldwide and $80 \%$ of people in developed countries have internet access today. The woman on the balcony's GPS tracker allowed her to keep a new kind of diary, similar to the diary that is automatically written for us by our computers and phones today, as our devices log our actions and movements. We may or may not examine, curate and share these automatically recorded traces of our lives. We may keep deliberate online diaries: a dedicated blog, photographs regularly posted to Instagram with careful descriptions, or just the occasional Facebook post about something that happened today: "I met a woman, on a balcony, and she made me think differently about what a diary might be."

In this chapter I will give you an overview of the early history of online diaries and blogs, and then examine how technology shapes the way we record 
our lives, and how technology records our lives for us. One of the most important differences between paper and online diaries is the size of the potential audience, and I will write about how people manage that publicity, either by embracing it, or by using ephemeral platforms, by using pseudonyms, or by only allowing a limited audience to read their posts. When the internet was new, that wasn't necessary, because the likelihood of meeting a neighbor or acquaintance from everyday life online was so very, very low.

\section{Early online diaries}

The first online diaries appeared around 1994, and were hand-coded by people who had taught themselves to create websites. One of the first online diaries was Justin Hall's Justin's Links, which is still active at links.net, though the style and content have changed considerably over the years. At first, the website was written as a meandering hypertextual story about Hall's life, but in 1996 Hall began posting dated diary entries that still linked and intermingled with his hypertextual autobiography. Hall didn't call his site a weblog until much later, because 'web log' at that time was used to refer to the statistics available to website administrators showing the number of visitors to a website. In 1997, Jorn Barger proposed that the term weblog be used to refer to websites that post links to interesting material with commentary ${ }^{3}$. Around that time, a number of handcoded weblogs became popular. Posts in these early weblogs was brief and although the comments usually had a clear individual voice and offered personal opinions, the content was usually comments on news stories and online finds rather than stories from the writer's life. Weblogs tended to be seen in opposition to online diaries, which were more confessional. In 1998, Open Diary became one 
of the first sites to provide easy web publication without users needing to know how to code or edit HTML ${ }^{4}$. Instead, users picked a layout from a set of templates, and wrote their entries into text boxes. 1999 saw the launch of sites for easily publishing weblogs, or blogs as they became known, including Pitas and Blogger. Within a few years, the once quite separate genres of online diaries and blogs merged. Blog posts became longer and more essayistic, often using a more personal voice, and online diaries came to include more essayistic material and commentary in addition to the autobiographical content.

By 2004 blogs were so popular that 'blog' was named word of the year by the Merriam-Webster, much as 'selfie' was named word of the year by Oxford Dictionaries in 2013, and both declarations were much discussed in the mainstream media. Around the same time as blog became the word of the year, commercial blogging took off, and we saw corporate blogging as well as individuals who created their own profitable businesses by blogging about their lives or about products. Today microcelebrities ${ }^{5}$ and influencers ${ }^{6}$ tend to use multiple platforms rather than a single blog, as early bloggers did. A popular contemporary fashion blogger may have hundreds of thousands of readers a day, but they are often spread across platforms such as Instagram, Facebook, Snapchat and a blog. Celebrities and influencers often use elements of personal diary-writing to forge connections with their fans and audiences.

Viviane Serfaty's 2004 study of blogging connects blogs to the traditions of the English Puritans, who used diaries as "a requirement of religious selfdiscipline", recounting "a spiritual journey towards personal salvation" > During the same period the Libertines developed the idea of "an inner space devoted to internal deliberation" (5), which may be said to be one of the sources of the 
modern divide between the private and the public. Serfaty writes that both blogs and diaries are usually written more for the sake of the writer than for the sake of the reader. They are used as mirrors, she argues, to reflect upon the self, more than they are used to project a particular image to the public, as might for instance be the case in an autobiography intended for publication.

Serfaty's book was published in 2004, before the commercialization of blogs ${ }^{8}$, and before social media went mainstream. While much of what she writes is still true of today's blogs, clearly many blogs are now much more about branding, monetization or constructing a particular image of the self, while much other use of social media is more about keeping in touch with friends or sharing quick jokes or observations than about self-improvement or developing ideas. A lot of the discussion that previously happened in self-hosted blogs has shifted to corporate-owned spaces like Twitter and Facebook, where the space to write is far more limited than in a traditional blog. Another shift is the increased emphasis on metrics: how many likes, shares or recommends did your post get? In the early days of blogging this was not visible to readers. You could see where discussions were taking place, but you couldn't calculate how important a blogger was based on numbers at the bottom of each post.

There are still non-commercial personal diaries online, and there are social media that allow a similar sharing of personal and intimate experiences as we saw in early online diary communities, though using video or still images with a little text instead of being mostly about writing. But perhaps the heyday of online diaries, or of diaries at all, is past. If you go to the Google Ngram Book Search and search all the books Google has digitized for the word "diary," or "dear diary," you will see the words are used more and more frequently until about the 
year 2000, and then usage begins to drop. That autumn evening on the balcony in Melbourne, just before blogs went mainstream, I caught a glimpse of a shift from a time when we wrote diaries to a time where we record our lives through technology.

\section{How technology shapes diaries}

There are many different ways of keeping a diary. My grandmother's diary from the cruise she took in the 1960s mostly consists of sparse notes: "Arrived Hong Kong about 10 pm." Two days later she wrote two words: "Shopping Kowloon," followed, a couple of days later, by "Left Hong Kong 10:30 am bound for Kobe." Her cruise diary is jotted down in a pocket-sized notebook covered in floral-patterned silk. Dates are printed on the pages: two days on each small page. There is not room for much more than notes of quick facts, and only rarely are there more personal notes. It is not that different from the woman on the balcony's GPS diary. It's a record of facts, not personal experiences, though for the person who records them, those facts may evoke a world of intimate details.

Many diaries, both online and on paper include explicit prompts. Dates printed on the pages create an expectation of short, but daily notes. A pregnancy journal, baby book or wedding album may have prompts that structure how the diarist records their life: describe your baby's first smile, first tooth, first birthday; glue in a photo of the groom waiting for the bride, the bride walking down the aisle, the kiss at the alter, the first dance. These material structurings of diary-writing are all founded on cultural practices and rituals: whether marking the passing of days by naming them, or celebrating life events in certain ways. 
When scrapbookers create albums documenting a baby's first year or a wedding, they are likely to include the same highlights even without the explicit prompts. Filters can be technological, as we see in the prompts and templates of a preprinted baby journal or the constraints and affordances of Instagram or Facebook or Blogger.com. Filters can also be cultural $:$ we expect to take a photo of the baby's first birthday and to write down baby's first steps and first tooth, whether or not the baby album specifically asks for this information. In the midtwentieth century, Pierre Bourdieu wrote about certain things as being photographable by families and amateurs: happy families, sunny vacations and celebrations ${ }^{10}$. Photo albums, baby albums and wedding albums are intended for sharing, and being semi-public, are curated in a different way than private diaries. Today we see a similar divide between semi-public media like Facebook or a blog and more private spaces for sharing personal experiences, such as Snapchat, an anonymous blog on Tumblr or a private Instagram account. We share different things depending on who we expect will see what we share.

Anonymous or pseudonymous diaries are an important part of online diary culture. Although commercial diarists and bloggers often use their full names, there is a strong parallel culture of people writing about their lives with no interest in monetizing their writing, and these people often use pseudonyms. This anonymity was one of the mainstays of popular early sites like OpenDiary.com, which was online from 1998-2014, and was important to many online diarists. In a study of Open Diary users in 2006-8, Annamari Martinviita found that many of their informants felt that the anonymity allowed them to write about very intimate details of their lives, and that the ability to communicate openly about their lives, with no fear of the conversations 
impacting upon their everyday lives, was very important to them ". With Facebook, using real names has become increasingly common in social media, but there are still many platforms where people share diary-like material either using a pseudonym or completely anonymously. For instance there are communities on Tumblr where people discuss sensitive topics like self-harm ${ }^{12}$ or sexuality ${ }^{13}$.

Are these diaries, though? Many of the Tumblr logs include diaristic posts, describing what the writer has experienced that day, but they also tend to include many other kinds of posts: images with little or no written description, reposted memes and excerpts from mass media content, and responses to other users' posts. In her ethnography of OpenDiary.com, Annamari Martinviita argues that diarists were able to write about quite intimate experiences because they were already familiar with writing personal diaries on paper. Also, the design of the site was also based on the idea of a private, paper diary: "on Open Diary, the traditional understandings related to diary-writing - total privacy and hiddenness - influenced the design to a much greater extent than seen in modern-day blogs" ${ }^{14}$.

The commercialization of blogs and the emphasis on quantified measures of popularity such as likes, shares and reads ${ }^{15}$ mean that bloggers not only expect their blogs to be public, there is a built-in expectation that you would want as many readers as possible. On OpenDiary.com, as Martinviita writes, "the more closed nature of the community meant that it was rare for a diarist to gain exposure outside the site, and for the majority of members the experience and aim of writing remained purely personal" ${ }^{\prime 16}$. 


\section{When technology writes for us}

Many of the photographs and personal stories parents share on Facebook are not dissimilar to the images Bourdieu saw as photographable in the 1960s: a newborn baby, a wedding, a happy family on vacation. As we collect more and more data about our personal lives on our phones and on social media platforms, services are appearing that promise to stictch together all our personal information into overviews, narratives or visualisations of our lives. In effect, these are a kind of automated diary, or perhaps automated memoirs"

Facebook's Timeline feature, released in 2011, is one example. The video they made a video to promote the feature begins with a blank, grey screen ${ }^{18}$. Two white boxes with text in Facebook-blue fade in: "Andy Sparks was born," says the first. The second specifies the date: "Aug 14, 1974." A grey line leads our eyes up the screen, and as though we are scrolling up a page we see photos move past: a mother and baby (Andy and his mother, we assume), childhood photos, photos from school, then a video of graduates in with red gowns throwing their red caps in the air. We speed past photos without being able to really see then, then the scroll pauses to show us a photo of Andy Sparks with an early 1990s-hairstyle and a girl next to him. His relationship status is shown beside the photo, and as we watch it shifts from "Single" to "In a relationship". Years flash by (we see the numbers 1997, 1998 and into the 2000s), and we start seeing more recent photos of the adult Andy with his girlfriend, then a wedding photo with the words "Married Rachel Hudson". Icons on a map show where he checked in during his honeymoon, then we start seeing photos of Rachel, pregnant and smiling at the beach, followed of course by baby photos and then lots of photos of videos of 
Andy and his growing child. The video ends with the words "Introducing Timeline" on a blue background.

Facebook's "Introducing Timeline" video also gives us a perfect example of Bourdieu's photographable images, and also shows how short, diary-like Facebook posts can be combined into a story of a life, a form of automated autobiography or memoir ${ }^{19}$. However, in 2016 Facebook quietly removed their Timeline feature. Perhaps we no longer want such neatly packaged lives? A parody of the Introducing Timeline video shows many of the problems involved in combining day-to-day recordings of life with the overall narrative of an autobiography or carefully curated wedding album ${ }^{20}$. Most of our Facebook posts are banal, and sometimes embarrassing in hindsight. The parody shows the life of "Andrea Sparks", a fictional character. Like Andy's timeline, Andrea's quickly moves towards love, but for her, relationships are a lot more serial than for Andy. "My first breakup", is the caption of a photo accompanied by the broken heart icon of a relationship status change from "In a relationship" to "Single". There are photos of drunken nights out, a photo a friend posted to her Timeline of her zipping up her jeans after a one-night-stand. We see the "In a relationship" and "Single" statuses flipping back and forwards. "Why live in the past? Goodbye old Andrea Sparks," the voiceover says, as we see the cursor move to the account settings, and select "Deactivate account".

Frivolous or embarrassing sharing, or "oversharing", is one of the many stereotypes of online diaries and self-representation in social media. But often this dismissal is evidence of a failure to recognise the value of the social. Social media are phatic, and a lot of what happens on Facebook and even in blogs is about establishing and maintaining social connections. 
Social media and apps increasingly write our diaries for us, and they focus on the quantifiable rather than the emotional or confessional, because that is what computers are good at. Individual apps keep track of your activities: Runkeeper or Endomondo tracks your runs, at the end of the year Spotify generates a report on what music you listen to, and Google Photos generates photo albums for you every time you take a trip, complete with maps of your journey and the photos you have taken neatly organized by time, date and place. When we connect apps to social media platforms, like Facebook, apps can even update each other. In her study of how Facebook users experience their apps automatically posting to their Facebook profile, Tanya Kant found that users see their identity on Facebook as a "carefully-crafted performance", and that inadvertent automatic posts can upset this, for instance if they were listening to something they think of as embarrassing on Spotify, and it gets posted to their Facebook feed. On the other hand, one of Kant's informants admitted to deliberately listening to songs they wanted their friends to see that they appreciate $^{21}$.

There are an increasing number of apps that promise to write your diary for you, and their marketing is remarkable. Consider these lines from STEP Journal's iTunes app store pitch: “STEP Journal assists you in capturing and telling the amazing story of your life. Life poetry told by sensors - minimal efforts and 100\% privacy. The true power of Automatic Journaling!" Or perhaps you would be more interested in the app Saga: "Be bold. Embrace your authentic self. Record your life automatically and share it effortlessly with the people you care about." As I discuss elsewhere, ${ }^{22}$. the idea of automated diaries seems at odds with the notion that we use diaries to make sense of our lives by telling our 
own stories. However, as Minna Ruckenstein has found, we narrativise our data as well as our lives. When we are shown quantified information about our days, such as steps walked or calories burned or heart rate variability (an indicator of stress), we retell our stories of what happened that day, adjusting memories to data and data to memories to create a story that will fit ${ }^{23}$

\section{Pseudonymous Diary-Writing}

A popular group of blogs is the general sphere of domestic blogs: mommy blogs, craft blogs, cooking blogs, home design blogs, gardening blogs and so on. These blogs can be highly professionalized, but most contain personal, diary-like aspects. Posts tend to be image-rich, and tell stories from the bloggers' everyday lives. Over the years, bloggers have grown increasingly adept at telling a general public about their days in a way that retains their own and their families' privacy. These blogs are not private diaries where everything is told. Far from it, bloggers often give pseudonyms to children and family members (dd for dear daughter, or more personalized pseudonyms like Miss A., Mr 13 or My Princess) and images are often framed and cropped so as to hide identifying characteristics. This elusion of identity is almost the opposite to Bourdieu's idea of the photographable: happy, smiling families. It is also a different mode of selfrepresentation to the face-centric selfies that are so common in other kinds of social media. Photos and stories in mommy blogs in particular often evoke an atmosphere or an emotion more than an exact sequence of events. For instance, a photo may show chubby toddler hands building a mud pie, but the child's face is not visible. Or you may see a teenager and a dog running through a field of flowers, but they are photographed from behind. 
Writing public diaries while maintaining privacy isn't only a concern for parents protecting their children, and it can be seen both in words and images. There is, for example, a whole genre of professors writing pseudonymous blogs about the challenges of combining academic work and a personal life ${ }^{24}$. On Tumblr or Reddit, you'll find young adults discussing sensitive topics like depression, self-harm or their sexual identities using similar strategies: they write using a pseudonym, photographs are cropped to hide the face, and there are no references to places or names in the text ${ }^{25}$. This allows them to find a community without exposing their identity. The communal aspect of these blogging communities is very reminiscent of the way many religious groups encouraged journaling as a spiritual practice for self-improvement ${ }^{26}$ although the topics are very different. On the internet, this shared work can be done quite separately from the social environent you inhabit at home, at school or at work.

\section{Ephemerality}

Online diaries also exist in a conflict between ephemerality and permanence. The Facebook Timeline spoof video shows this perfectly: sharing photos of a drunken binge can be perfectly appropriate between friends, but it is not necessarily something you want to be a permanent part of the online, publicly accessible narrative of your life. Snapchat is built around true ephemerality: messages disappear once they are viewed, and although you can share images and videos to your "Story", which is often used a lot like a visual diary, stories disappear after 24 hours. There is no permanent record. This kind of disappearing diary might be what we need now that diaries have become social. 
While traditional photoalbums are visual, shared, family diaries that are intended to be passed down through generations, personal paper diaries are often more temporary. Of course they are often saved, and the very format of the book means that individual entries will usually not be thrown out because they are part of a book. But many diaries are eventually burnt or thrown out when their writer rereads them, years afterwards, and is embarrassed, or they may be destroyed to protect the privacy of the writer.

Snapchat is used by many as a social diary that self-destructs every day. In its first years, Snapchat was a visual messaging system where messages disappeared once read. Now it also allows users to post 'stories' that are visible either to the user's friends or to everyone, and that disappear after 24 hours. Stories are sequences of snaps, that is, sequences of still images and 10-secondor-less videos. Images can have writing and drawings on them, and people often narrate a voiceover on their videos. In practice, Snapchat Stories are often used as a kind of shared diary. Most people who create stories share individual snaps from their day: quick photos of where they are and what they are doing, a series of selfies with text explaining a disappointment, a surprise or something they are looking forwards to, a series of videos showing how the Snapchatter gets on the bus on their way to a party, building up anticipation.

Snapchat is also increasingly being used by marketers, celebrities and influencers who tend to create more structured stories, stringing together a series of snaps to make a short cohesive video about something they did today. Perhaps because of the inherent impermanence of Snapchat, you will sometimes see quite confessional posts there. When studying Snapchat stories, I followed a lot of people who had posted their Snapchat user names on public forums on the 
web, asking people to follow them ${ }^{27}$. One was a school teacher who mostly posted happy snaps of her home and her husband and her cat, until one day, she posted a string of crying snaps, speaking into the camera with tears streaming down her cheeks as she told us how she hated her job, how the kids she taught were great but the boss was crazy and she was going to quit. She and her husband were planning to move back to the small town where his parents were from and live in their basement.

After that day, her snaps went back to the standard happy fare, and there have only been a very few references to the move or to her job. A new follower, or someone who hadn't checked Snapchat on that day, would never have known. A snapchat storyteller (who might be thought of as a video diarist), has to repeat information from previous days if they want to be sure that all current viewers know about it. You start afresh every day - unless you are a major celebrity, in which case you may find key Snapchat stories have been screencaptured and republished. That happened with one of Snapchat's most popular users, DJ Khaled (@djkhaled), whose snaps from when he got lost on his jetski were reposted by a number of media outlets, and of course posted to YouTube ${ }^{28}$.

Another person I followed had been creating complex, quite artistic stories almost daily, but then posted a series of very emotional snaps about how his friend had been in a car crash. He stopped posting at all after that.

Although Snapchat may be particularly conducive to this kind of confessional, intensely emotional honesty, confessional posts also can be found on blogs. In the early years of blogging, there were several cases heavily reported in the media where bloggers were fired for indiscreet blog posts. In part this was 
due to "digital dualism" ${ }^{29}$, the sense that the internet was a separate domain from our everyday lives, with few consequences flowing between the two spheres. In the early days, so few people were online that you were very unlikely to meet a neighbor or colleague online. Obviously this has changed. Dooce was probably the first and most famous of the bloggers who were fired 'for blogging': she wrote an angry post about her employer without considering that as she was blogging using her full name, her employer was likely to see what she wrote ${ }^{30}$.

\section{A Time of Transition}

Online diaries and blogs are genres in transition, and that have been in transition for the last twenty years. Words merge with images, video with text, and people spread their stories across different platforms: Facebook, Tumblr, Snapchat, a blog. On another level, things haven't really changed that much. Online and offline, we record aspects of our lives. We share our records with some people. Sometimes we destroy our diaries, or publish them. We start a diary and forget about it. We log every location we are at for a while, and then get bored with that. We find the diaries we wrote as teenagers and burn them. Or we delete our old Facebook posts.

As technologies change, we record and share our lives in different ways. Today many young people share videos and images on Snapchat or Instagram, telling their friends about their lives. Photographs and videos have become far more central in our self-representations than they were when my grandmother jotted down notes from her cruise. Data about our lives is recorded automatically as well, to an extent that I did not imagine, back in 2001 as the woman on the balcony told me she thought of her GPS device as "a sort of of diary." 
The ways we write about and record our lives are changing. But we don't stop writing.

"Philippe Lejeune, "Autobiography and New Communication Tools," in Identity Technologies: Constructing the Self Online, trans. Katherine Durnin, Wisconsin Studies in Autobiography (Madison: University of Wisconsin Press, 2014), 247.

2 Peter Heehs, Writing the Self: Diaries, Memoirs, and the History of the Self (New York: Bloomsbury, 2013), 8.

${ }^{3}$ Jill Walker Rettberg, Blogging, 2nd ed. (Cambridge: Polity Press, 2014), 8.

${ }^{4}$ Rettberg, 9.

"Theresa M. Senft, "Microcelebrity and the Branded Self," in A Companion to New Media Dynamics, ed. John Hartley, Jean Burgess, and Axel Bruns (Chicester: Wiley, 2013), 347-55; Alice Marwick, Status Update: Celebrity, Publicity, and Branding in the Social Media Age (New Haven: Yale UP, 2013).

${ }^{6}$ Crystal Abidin, "Communicative $\bullet$ Intimacies: Influencers and Perceived Interconnectedness," Ada: A Journal of Gender, New Media \& Technology 8 (2015), http://adanewmedia.org/2015/11/issue8-abidin/.

- Viviane Serfaty, The Mirror and the Veil: An Overview of American Online Diaries and Blogs (Amsterdam: Amsterdam Monographs in American Studies, 2004), 5 .

${ }^{8}$ Rettberg, Blogging, Chapter 5.

' Jill Walker Rettberg, Seeing Ourselves Through Technology: How We Use Selfies, Blogs and Wearable Devices to See and Shape Ourselves (Basingbroke: Palgrave, 2014), 22. 1990).

${ }^{10}$ Pierre Bourdieu, Photography: A Middle-Brow Art (Stanford: Stanford UP,

"Annamari Martinviita, "Online Community and the Personal Diary: Writing to Connect at Open Diary," Computers in Human Behavior 63 (October 2016): 672-82, https:/ / doi.org/10.1016/j.chb.2016.05.089.

${ }^{12}$ Yukari Seko and Stephen P. Lewis, "The Self-harmed, Visualized, and Reblogged: Remaking of Self-Injury Narratives on Tumblr," New Media \& Society, July 28, 2016, 1461444816660783, https: / / doi.org/10.1177/1461444816660783.

${ }^{13}$ Katrin Tiidenberg, "Boundaries and Conflict in a NSFW Community on Tumblr: The Meanings and Uses of Selfies," New Media \& Society, January 14, 2015, https: / / doi.org/10.1177/1461444814567984.

${ }^{14}$ Martinviita, "Online Community and the Personal Diary," 680.

${ }^{15}$ Benjamin Grosser, "What Do Metrics Want? How Quantification Prescribes Social Interaction on Facebook," Computational Culture, no. 4 (2014), http: / / computationalculture.net/article/ what-do-metrics-want; Marwick, Status Update.

${ }^{16}$ Martinviita, "Online Community and the Personal Diary," 680.

${ }^{17}$ Jill Walker Rettberg, "Apps as Companions: How Quantified Self Apps Become Our Audience and Our Companions," in Self-Tracking: Empirical and Philosophical Investigations, ed. Btihaj Ajana (Palgrave Macmillan, 2018), https: / / doi.org/10.1007/978-3-319-65379-2_3. 
${ }^{18}$ Facebook, Introducing Timeline, Vimeo (Facebook, 2011).

${ }^{19}$ Rettberg, Seeing Ourselves, chapter 4.

${ }^{20}$ Jahnna Lee Randall, Introducing Facebook Timeline - (Spoof/Parody), YouTube video, 2012, https: / / www.youtube.com/watch?v=Y4LMhYcglFY.

${ }^{21}$ Tanya Kant, "'Spotify Has Added an Event to Your Past': (Re)Writing the Self through Facebook's Autoposting Apps," The Fibreculture Journal, no. 25 (2015), https:// doi.org/10.15307/fcj.25.180.2015.

${ }_{22}$ Rettberg, Seeing Ourselves, 47-49.

${ }^{23}$ Minna Ruckenstein, "Visualized and Interacted Life: Personal Analytics and Engagements with Data Doubles," Societies 4, no. 1 (February 18, 2014): 6884, https: / / doi.org/10.3390/ soc4010068; Rettberg, Seeing Ourselves, 69-70, 87.

${ }^{24}$ Rettberg, Blogging, 125-28.

${ }_{25}$ Emily van der Nagel and Jordan Frith, "Anonymity, Pseudonymity, and the Agency of Online Identity: Examining the Social Practices of r/Gonewild," First Monday 20, no. 3 (February 22, 2015),

https: / / doi.org/10.5210/ fm.v20i3.5615; Tiidenberg, "Boundaries and Conflict."

${ }^{26}$ Rettberg, Seeing Ourselves, 5-6.

${ }^{27}$ Jill Walker Rettberg, "Snapchat," in Appified, ed. Jeremy Wade Morris and Sarah Murray (Ann Arbor: University of Michigan Press, 2017).

${ }^{23}$ YoungJizzle, DJ Khaled Jet Ski Adventure 12.14.15 ORIGINAL VIDEO, 2015, https: / / www.youtube.com/watch?v=kkuR8ODzo1Q.

${ }^{29}$ Nathan Jurgensen, "Digital Dualism versus Augmented Reality," Cyborgology (blog), February 24, 2011,

https: / / thesocietypages.org/ cyborgology / 2011/02/24/digital-dualism-versusaugmented-reality /.

${ }^{30}$ Rettberg, Blogging, 18.

References

Abidin, Crystal. "Communicative $\bullet$ Intimacies: Influencers and Perceived Interconnectedness." Ada: A Journal of Gender, New Media \& Technology 8 (2015). http://adanewmedia.org/2015/11/issue8-abidin/.

Bourdieu, Pierre. Photography: A Middle-Brow Art. Stanford: Stanford UP, 1990.

Facebook. Introducing Timeline. Vimeo. Facebook, 2011.

Grosser, Benjamin. "What Do Metrics Want? How Quantification Prescribes Social Interaction on Facebook." Computational Culture, no. 4 (2014). http://computationalculture.net/article/what-do-metrics-want.

Heehs, Peter. Writing the Self: Diaries, Memoirs, and the History of the Self. New York: Bloomsbury, 2013.

Jurgensen, Nathan. "Digital Dualism versus Augmented Reality." Cyborgology (blog), February 24, 2011. https://thesocietypages.org/cyborgology/2011/02/24/digital-dualismversus-augmented-reality/. 
Kant, Tanya. "Spotify Has Added an Event to Your Past': (Re)Writing the Self through Facebook's Autoposting Apps.” The Fibreculture Journal, no. 25 (2015). https://doi.org/10.15307/fcj.25.180.2015.

Lejeune, Philippe. “Autobiography and New Communication Tools." In Identity Technologies: Constructing the Self Online, translated by Katherine Durnin, 247-58. Wisconsin Studies in Autobiography. Madison: University of Wisconsin Press, 2014.

Martinviita, Annamari. "Online Community and the Personal Diary: Writing to Connect at Open Diary." Computers in Human Behavior 63 (October 2016): 672-82. https://doi.org/10.1016/j.chb.2016.05.089.

Marwick, Alice. Status Update: Celebrity, Publicity, and Branding in the Social Media Age. New Haven: Yale UP, 2013.

Nagel, Emily van der, and Jordan Frith. "Anonymity, Pseudonymity, and the Agency of Online Identity: Examining the Social Practices of r/Gonewild." First Monday 20, no. 3 (February 22, 2015). https://doi.org/10.5210/fm.v20i3.5615.

Randall, Jahnna Lee. Introducing Facebook Timeline - (Spoof/Parody). YouTube video, 2012. https://www.youtube.com/watch?v=Y4LMhYcglFY.

Rettberg, Jill Walker. "Apps as Companions: How Quantified Self Apps Become Our Audience and Our Companions." In Self-Tracking: Empirical and Philosophical Investigations, edited by Btihaj Ajana. Palgrave Macmillan, 2018. https://doi.org/10.1007/978-3-319-65379-2_3.

--—. Blogging. 2nd ed. Cambridge: Polity Press, 2014.

---. Seeing Ourselves Through Technology: How We Use Selfies, Blogs and Wearable Devices to See and Shape Ourselves. Basingbroke: Palgrave, 2014.

---. "Snapchat." In Appified, edited by Jeremy Wade Morris and Sarah Murray. Ann Arbor: University of Michigan Press, 2017.

Ruckenstein, Minna. "Visualized and Interacted Life: Personal Analytics and Engagements with Data Doubles." Societies 4, no. 1 (February 18, 2014): 68-84. https://doi.org/10.3390/soc4010068.

Seko, Yukari, and Stephen P. Lewis. "The Self-harmed, Visualized, and Reblogged: Remaking of Self-Injury Narratives on Tumblr." New Media \& Society, July 28, 2016, 1461444816660783. https://doi.org/10.1177/1461444816660783.

Senft, Theresa M. "Microcelebrity and the Branded Self." In A Companion to New Media Dynamics, edited by John Hartley, Jean Burgess, and Axel Bruns, 347-55. Chicester: Wiley, 2013. 
Serfaty, Viviane. The Mirror and the Veil: An Overview of American Online Diaries and Blogs. Amsterdam: Amsterdam Monographs in American Studies, 2004.

Tiidenberg, Katrin. "Boundaries and Conflict in a NSFW Community on Tumblr: The Meanings and Uses of Selfies.” New Media \& Society, January 14, 2015. https://doi.org/10.1177/1461444814567984.

YoungJizzle. DJ Khaled Jet Ski Adventure 12.14.15 ORIGINAL VIDEO, 2015. https://www.youtube.com/watch?v=kkuR8ODzo1Q. 